
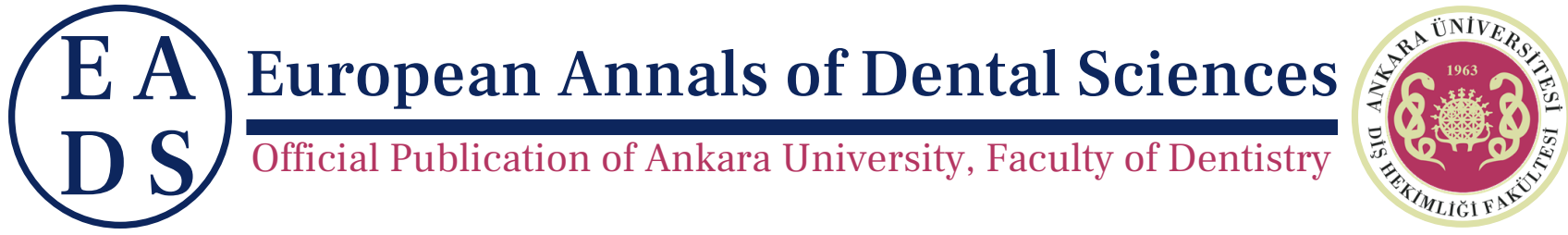

EADS, 2021, 48 (Suppl 1), S20-22

\title{
Evaluation of Clinical Students' Perspectives and Satisfaction Levels on Practical Practices at the Faculty of Dentistry of Tokat Gaziosmanpaşa University in the
} Covid-19 Pandemic

\author{
Işıl Sarıkaya \\ Gaziosmanpaşa University, Faculty of Dentistry, Department of Prosthodontics. Tokat, Turkey \\ Corresponding Author; sarikayaisil@gmail.com
}

\begin{abstract}
Purpose: It was aimed to reveal the perspectives and satisfaction levels of 4 th and 5 th grade-clinical students who go on practice education at Tokat Gaziosmanpaşa University Faculty of Dentistry in the 2020-2021 Academic Year.

Methods: Within the scope of the study, 146 students in total, who did their face-to-face internship between October 5 and December 11, 2020, were asked to participate in an online survey with 10 questions. Clinical students were asked about their perspective on Covid-19 infection, whether they felt safe in their dental practice, their families' level of anxiety about their internship, and whether they voluntarily chose dentistry.

Results: According to the survey results; $15.1 \%$ of the students agree (TA), $27.4 \%$ agree (A), 37\% partially agree (PA), $13 \%$ disagree (D) with the statement "I am pleased to have internships since the beginning of the term" $7.5 \%$ of them answered, "Strongly disagree" (SD). Pearson's chi-square test was used in the statistical analysis of the answers given by 4 th and 5 th-grade students to the first 9 questions of the questionnaire consisting of the same questions. According to the survey results, it was also observed that most students chose the dentistry profession of their own will (TA 39\%, A 36.3\%, PA 13.7\%). The number of students who think they feel safe in terms of infection control during their internship is $60 \%$ in total (TA 5.5\%, A 17.1\%, PA 37.7\%).

Conclusion: Despite the increasing number of cases until today, it is thought that the process has been successfully managed and that the students have gained experience in practical training, albeit limited.
\end{abstract}

Key words: Clinical students; Covid-19 Pandemic; Dental Practices; Dentistry Education

\section{Introduction}

In December 2019, a coronavirus that was not detected in humans before was identified in Wuhan, China. ${ }^{1}$ The COVID-19 outbreak, declared as a pandemic by the World Health Organization (WHO) as of March 12, 2020; continues to threaten humanity physically, spiritually, and socially. It has been observed that international travel plays a major role in the spread of COVID- ${ }^{2} 19$ between countries, and it has been reported that it can be transmitted directly from person to person through saliva and respiratory droplets, contact, and any object that has come into contact with the virus. ${ }^{3,4}$ The very small particle diameter of the aerosols formed during dental applications increases the risk of infection of dentists and auxiliary staff. Dentists and auxiliary staff are in close contact with patients during the procedures in dental clinics. It is known that a large number of virus-contaminated droplets and aerosols spread into the environment during interventional procedures. Therefore, dentists are constantly exposed to patients' saliva, blood, respiratory tract secretions, and other contaminated body fluids.

Dentistry Undergraduate Education is a five-year practiceoriented education. In the first three years of education, students develop their knowledge and skills to prepare for the clinic, which we call preclinical, while in the last two years, 4 th and 5th grade (clinical) students perform dental treatments at the bedside. The use of the clinical environment in dentistry education is extremely important in terms of increasing the speed of students' experience and practice. ${ }^{5,6}$ This process is quite difficult for educators as well as students. ${ }^{7}$ Besides, during the pandemic period, the movement 
area of the trainers is very limited. Even decision-making processes have been quite painful due to the fluctuating course of the pandemic.

The Ministry of Health General Directorate of Health Services recommended that dentists only perform emergency treatments and postpone non-urgent procedures due to the pandemic in article 3 of the letter on the postponement of elective procedures and other measures to be taken, dated 17.03.2020 and numbered 14500235403.99 / 00114959156. In this context, with the start of the Covid-19 epidemic, face-to-face undergraduate education was suspended in our Faculty on March 16, 2020, based on the relevant YÖK (Higher Education Institution) decision. Distance education and theoretical and practical training continued until the end of the 2019-2020 academic year. On July 9, 2020, the Study Guide and Infection Control Measures in Health Institutions in the COVID-19 Pandemic were published by the Ministry of Health. ${ }^{5}$ In our Faculty, as of July, interrupted patient treatments, except for emergency treatments, were carried out in qualified booths prepared following the relevant guidelines of the Ministry of Health.

As of July 2020, the triage practice was initiated at the admission of patients to our Faculty, and after taking fever measurements and anamnesis, the patient was examined by the on-duty physician in the patient admission unit, and limited patient entry to our Faculty was provided hourly. Due to the very low number of cases in our faculty clinics, where one-third of the capacity is worked in July October, on October 5,2020 , clinical students in grades 4 and 5 were called to the Faculty. Priority in internship practices was given to internships that could not be taken in the previous academic year. By keeping the number of dams low, the student was provided with training as a practitioner-observer. The tools and equipment used by students during clinical practices are provided by our faculty, and the sterilization and cleaning of the units are carried out by our faculty staff.

The aim of the present study to reveal the perspectives and satisfaction level of practice training of 4 th and 5th-grade clinical students in the 2020-2021 Education and Training year at Tokat Gaziosmanpaşa University Faculty of Dentistry. The hypothesis of the study was established that clinical students' level of anxiety about covid-19 is low and their level of satisfaction with their internship training is high.

\section{Methods}

The present study was carried out with the number of "21-KAEK029" permission of the Clinical Research Ethics Committee of Medical School of Tokat Gaziosmanpaşa University.

In our Faculty clinics, dentistry service has been continued based on the relevant circulars of YÖK (Higher Education Institution) and the Ministry of Health, which are constantly updated during the pandemic process, the algorithms of the Ministry of Health regarding COVID-19, the study guide of the Ministry of Health COVID-19 pandemic and the infection control methods guide. As of October 5, 2020, our 4th and 5th-grade students were kept in clinics for a limited time with divided groups and started their internship training at the bedside. For this prospective study, clinical students were asked to fill a volunteer survey (Table 1). In the questionnaires using the five-level Likert Scale (I totally agree, I agree, I partially agree, I disagree, I strongly disagree). The last question was asked differently to the 4 th and 5th-grade students, and the 5 th-grade students said, "If I graduated today, I would feel qualified as a dentist". It was aimed to learn the level of participation to the 4 th-grade students with the statement "I think distance education will be sufficient in completing my dentistry education".

In the study, the required sample size was determined as approximately 145 with $80 \%$ power, $0.5 \%$ error level, and 0.03 effect size. The distribution of qualitative variables according to the groups was analyzed statistically with the Pearson chi-square test. Statistical
I am pleased to have been doing internships since the beginning of the term

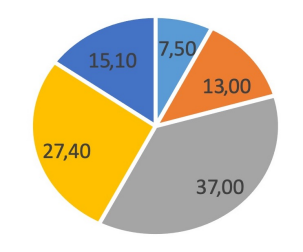

$$
\text { "SD-- "D- "PA "A+" TA++ }
$$

Figure 1. Presentation of the answers to the question "I am pleased to have internships since the beginning of the term" on the pie chart.

significance level was determined as $\mathrm{p}<0.05$. Statistical analysis of the data obtained was made using the SPSS V.20 package program (SPSS for Windows, Version 20; SPSS Inc, Chicago, USA).

\section{Results}

It has been observed that the students who answered "I think the practices I do at the bedside are sufficient in my internships" are mostly fourth-grade students with the answer "I disagree (34.9\%) and strongly disagree (11.6\%). The answers given to the question "I think the practices I do at the bedside are sufficient in my internships" showed a statistically significant difference between 4 th and 5 th-grade students $(\mathrm{p}<0.001)$. There was no significant difference between the other answers $(p<0.05)$.

Presentation of the answers to the question "I am pleased to have internships since the beginning of the term" on the pie chart (Figure 1). Presentation of the answers to the question " Covid-19 is very risky in terms of Dentistry" on the pie chart (Figure 2).

\section{Discussion}

Due to the results (Figure 1 and Figure 2); the hypothesis of the study' -clinical students' level of anxiety about covid-19 is low and their level of satisfaction with their internship training is high-was accepted. Dentistry undergraduate education is a practice-oriented education. In this process, Covid-19 provided a limited range of motion for educators in student education. The processes experienced in the Covid-19 pandemic were dynamically monitored during the March-December 2020 process, and necessary protective measures were taken for our intern students. In the Faculty of Dentistry of Tokat Gaziosmanpaşa University, the internship practice training of 4th and 5th-grade undergraduate students in the 2020-2021 Education and Training year was carried out by modifying them with diluted groups under pandemic conditions and continues.

Given the question "My family is worried about my internship" answers have been that agree $(\% 27,40)$, and totally agree $(\% 40,40)$ was found highly percentage. This may be due to the increase in cases seen in Tokat province especially in November.

In our faculty, internships are performed as Prosthetics and Oral and Maxillofacial Surgery major clinical practice for two months-, and others as small clinical practice for -one month. During the clinical practice, the students were divided into small groups (as five or six students), and in each department, the student shift method was worked as much as the cabin allocated to the students. Between October and December, a fourth and fifth-grade student was diagnosed with covid-positive and again two fifth-grade students were quarantined by contact. Between 5 October and 20 December, 10 of our staff, 3 of whom are dentists, 7 of which are clinical support staff, were diagnosed with covid-positive. It can be said that students in the clinical environment take the situation seriously.

Even the examination was not carried out except in the cabins, 
Table 1. Questions of "Dentistry internship applications covid-19 relationship" survey

Dentistry internship applications covid-19 relationship

1. I am pleased to have been doing internships since the beginning of the term.

2. I think that the applications I do at the bedside during my internships are sufficient.

3. Covid-19 infection also carries a risk for dentistry just like other infections.

4. Covid-19 infection is very risky for dentists.

5. I can access the necessary personal protective equipment during my internships.

6. I feel safe in terms of infection control during my internships.

7. My family is worried about my internship.

8. I am pleased to choose the dentistry profession.

9. I chose the dentistry profession of my own will.

10. I think distance education will be sufficient in completing my dentistry education (for 4 th grade). If I graduated today, I would feel qualified as a dentist (for 5 th degree)

Covid-19 infection is very risky for dentists

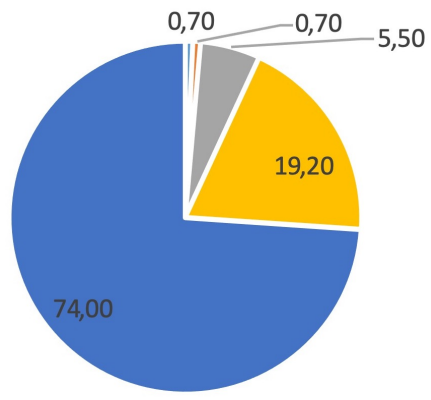

" SD-- "D- " PA "A+ "TA++

Figure 2. Presentation of the answers to the question " Covid-19 is very risky in terms of Dentistry" on the pie chart.

and after each patient, the physician was disinfected with the disinfectants used in the disinfection of the operating rooms in the cabin he worked. Also, all clinical staff was given washable gowns daily and their cleaning was maintained by our Faculty. Again, a protective N 95 mask was given to each employee once a week. Protective overalls have been supplied and given to the personnel who wish. In this way, the necessary personal protective equipment was supplied by our faculty, and the operation continues in this way. They protected themselves better. At the same time, they were away from the social environment by being in school.

Given the question "If I graduated today, I would feel qualified as a dentist (for 5th degree)" -answers have been that agree (\%22,10), and totally agree $(\% 23,40)$ was been half-and-half. Following the students of the faculties who continue their education online on social media may have encouraged the students. In the last year, it includes training with intensive bedside practices in dentistry education. Communicating with a large number of patients is very important in increasing professional competence. The main limitation of our survey is that it is a small-scale study. It sets an example for larger-scale studies by adding different faculty-clinical students.

\section{Conclusion}

It was observed from the results that the satisfaction of the clinical students with their education was at a satisfactory level.

\section{Author Contributions}

All authors have contributed to; conception and design of the study, data collection and analysis, writing the manuscript, approval of the final version to be submitted.

\section{Conflict of Interest}

Authors declare that they have no conflict of interest.

\section{Authors' ORCID(s)}

I.S. $\quad 0000-0002-2172-4724$

\section{References}

1. Lu H, Stratton CW, Tang YW. Outbreak of pneumonia of unknown etiology in Wuhan, China: The mystery and the miracle. J Med Virol. 2020;92(4):401-402. doi:10.1002/jmv.25678.

2. WHO Director-General's opening remarks at the media briefing on COVID-19 March 2020 Geneva [Web Page];. Available from: https://www . who.int/dg/speeches/detail/who-director-gene ral-s-opening-remarks-atthe-media-briefing-on-covid-19 ---11-march-2020 [cited 28/3/20].

3. Rodríguez-Morales AJ, MacGregor K, Kanagarajah S, Patel D, Schlagenhauf P. Going global - Travel and the 2019 novel coronavirus. Travel Med Infect Dis. 2020;33:101578. doi:10.1016/j.tmaid.2020.101578.

4. To KK, Tsang OT, Yip CC, Chan KH, Wu TC, Chan JM, et al. Consistent Detection of 2019 Novel Coronavirus in Saliva. Clin Infect Dis. 2020;71(15):841-843. doi:10.1093/cid/ciaa149.

5. Covid 19, Sağlık Kurumlarında Çalışma Rehberi ve Enfeksiyon Kontrol Önlemleri [Web Page];. Available from: https ://dosyah astane.saglik.gov.tr/Eklenti/174279, covid19saglikkurumla rindacalismarehberiveenf eksiyonkontrolonlemleripdf .pdf?0 " [cited 28/3/20].

6. Albino JE, Young SK, Neumann LM, Kramer GA, Andrieu SC, Henson L, et al. Assessing dental students' competence: best practice recommendations in the performance assessment literature and investigation of current practices in predoctoral dental education. J Dent Educ. 2008;72(12):1405-35.

7. AKALTAN KF. Fakültenin geliştirilmesi: Lisans diş hekimliği eğitmenlerinin görev ve yeterlikleri. Selcuk Dental Journal. 2019;6(5):92-108. 